\title{
Lycopene from heat-induced cis-isomer-rich tomato sauce is more bioavailable than from all-trans-rich tomato sauce in human subjects
}

\author{
Nuray Z. Unlu ${ }^{1}$, Torsten Bohn ${ }^{1}$, David M. Francis ${ }^{2}$, Haikady N. Nagaraja ${ }^{3}$, Steven K. Clinton ${ }^{4}$ and \\ Steven J. Schwartz ${ }^{1 *}$ \\ ${ }^{1}$ Department of Food Science and Technology, The Ohio State University, Columbus, 2015 Fyffe Road, OH 43210, USA \\ ${ }^{2}$ Department of Horticulture and Crop Science, The Ohio State University, 1680 Madison Avenue, Wooster, OH 44691, USA \\ ${ }^{3}$ Department of Statistics, The Ohio State University, 1958 Neil Avenue, Columbus, OH 43210, USA \\ ${ }^{4}$ Department of Internal Medicine, Division of Hematology and Medical Oncology, The Ohio State University, 320 West 10th \\ Avenue, Columbus, OH 43210, USA
}

(Received 18 October 2006 - Revised 3 January 2007 - Accepted 9 January 2007)

\begin{abstract}
Lycopene is present mainly as cis-isomers in human serum and tissues whereas all-trans-lycopene predominates in tomato products, suggesting that all-trans-lycopene is isomerised in the body or is less bioavailable. The objectives of the present study were to develop processing conditions for tomatoes to obtain products with different cis-trans-lycopene isomer distribution and to assess their bioavailability. Healthy adult subjects ( $n$ 12) were recruited for this randomised cross-over trial. Each intervention was preceded by a 2-week washout period. Two tomato sauces, one rich in all-trans-lycopene (32.5 mg total lycopene/100 g sauce; $5 \%$ cis-isomers), the other high in cis-lycopene (26.4 mg total lycopene/100 g sauce; $45 \%$ cis-isomers), were produced by different heat-processing techniques. Each sauce $(150 \mathrm{~g})$ was served in a standardised meal at 08.00 hours after overnight fasting. Plasma TAG-rich lipoprotein fractions over $9.5 \mathrm{~h}$ following test-meal consumption as a measure of lycopene absorption were obtained and expressed as baseline-corrected area under the concentration $v$. time curves (AUC), using HPLC-electrochemical detection. AUC values adjusted for the amount lycopene consumed showed that total, total cis-, and all-trans-lycopene responses were significantly higher from the cis-isomer-rich sauce, compared with the all-trans-rich sauce, being 7.30 (SEM 1.45) v. $4.74(\mathrm{SEM} 1.08) \mathrm{nmol} \times \mathrm{h} / \mathrm{l}(P=0.002), 3.80(\mathrm{SEM}$ $0.76)$ v. $1.98($ SEM 0.37$) \mathrm{nmol} \times \mathrm{h} / \mathrm{l}(P=0.0005)$ and $3.50($ SEM 0.76$)$ v. $2.76($ SEM 0.76$) \mathrm{nmol} \times \mathrm{h} / \mathrm{l}(P=0.01)$, respectively. The present study demonstrates significant lycopene bioavailability from cis-lycopene-rich tomato sauce and highlights the importance of considering isomer-distribution for lycopene bioavailability. Furthermore, processing parameters can be controlled to alter isomer patterns of tomato products and influence lycopene bioavailability.
\end{abstract}

Cis- and trans-lycopene: Heat processing: Postprandial absorption: Plasma triacylglycerol-rich lipoprotein fraction

Lycopene, the predominant carotenoid in tomatoes and tomato products responsible for the red colour, has attracted considerable attention as epidemiological evidence continues to suggest that it may provide protection against a number of cancers and other degenerative diseases (Giovannucci, 1999; Nguyen \& Schwartz, 2000; Khachik et al. 2002). The observation that serum and tissue lycopene consists of between 50 and $90 \%$ cis-lycopene isomers, whereas tomatoes and tomato-based products contain mainly all-trans-lycopene, has led to the hypothesis that cis-isomers of lycopene are produced during food processing, cooking, or digestion or are more bioavailable (Erdman, 2005). Improved absorption of lycopene $c i s$-isomers is hypothesised to result from greater solubility in mixed micelles and a lower tendency to aggregate (Stahl \& Sies, 1992; Boileau et al. 1999), a hypothesis supported by rodent studies (Boileau et al. 1999; Korytko et al. 2003). Although most commercially processed tomato products such as juice, paste, soup and ketchup contain a rela- tively low percentage of $c i s$-isomers $(<10 \%)$, aggressive food processing or cooking has been shown to increase cis-isomer content (Shi \& Le Maguer, 2000). The greatest increase in cis-isomer formation was observed when tomato products were heated in the presence of oil (Stahl \& Sies, 1992; Schierle et al. 1997; van het Hof et al. 1998). Thus, research conducted so far suggests that lycopene cis-isomer formation is usually not observed at the mild temperatures commonly employed in most commercial food processing but is enhanced by the presence of oil at medium or higher processing and cooking temperatures.

The presence of elevated levels of lycopene cis-isomers in human biological samples compared with fresh tomatoes may also have biological significance, but this remains speculative (Clinton et al. 1996). Cis-isomers may show unique tissue biodistribution patterns or perhaps distribute differently within cellular compartments to influence cell functions and responses to physiological or toxic stimuli in the

\footnotetext{
Abbreviations: AUC, area under the concentration v. time curve; OSU, Ohio State University; TRL, TAG-rich lipoprotein.

* Corresponding author: Dr Steven J. Schwartz, fax +1 614292 4233, email schwartz.177@osu.edu
} 
external or intracellular environment. Thus, it is hypothesised that modification of the cis- and trans-lycopene-isomer pattern of foods may allow investigators to achieve targeted changes in absorption and distribution of specific carotenoid isomers in order to influence biological effects and health outcomes.

The objective of the present study was to develop two similar tomato sauces with high and low cis-lycopene-isomer content by different processing techniques. In addition, our goal was to compare postprandial absorption patterns of lycopene isomers in human subjects after a single-meal consumption of these sauces to address the question whether there is a preferential uptake of lycopene from the cis-isomer-rich product and whether further in vivo isomerisation takes place. Furthermore, we tested the feasibility of shortening the time- and labour-intensive $10 \mathrm{~h}$ postprandial blood collection with eight samples to a four-sample collection following testmeal consumption. Lycopene absorption was assessed by analysing the plasma-triacylglycerol (TAG)-rich lipoprotein (TRL) fraction of plasma, reflecting newly absorbed carotenoids as a measure of bioavailability, as compared with a large number of human studies typically investigating lycopene bioavailability based on plasma response (McEligot et al. 1999; Rao, 2004; Frohlich et al. 2006).

\section{Experimental methods}

\section{Subjects}

Twelve healthy, non-pregnant, non-smoking subjects (six male and six female; age 19-43 (median 29) years) were recruited for the study. Eligibility was based on a screening test for normal blood lipid profiles (cholesterol, TAG) and a health and lifestyle questionnaire. Exclusion criteria were hyperlipidaemia, any history of chronic gastrointestinal disease, use of medications affecting lipid metabolism, regular use of carotenoid-containing supplements, and frequent alcohol consumption. The study was approved by the Biomedical Sciences Institutional Review Board of The Ohio State University (OSU) and written informed consent was obtained.

\section{Tomato sauce processing}

High-lycopene-variety tomatoes, FG99-218 (Department of Horticulture and Crop Science, OSU, Wooster, OH, USA), were used to produce tomato sauces. FG99-218 was homozygous for the dark green $(d g)$ gene and for the old-gold crimson $\left(\mathrm{og}^{c}\right)$ gene. Plants were grown with $30 \mathrm{~cm}$ within-row spacing and $1.5 \mathrm{~m}$ between-row spacing at OSU North Central Agricultural Research Station (near Fremont, OH, USA), following standard practices (Precheur, 2000). Following harvest, tomatoes were immediately processed $\left(104^{\circ} \mathrm{C}, 30 \mathrm{~min}\right)$ into canned tomato juice. Afterwards, tomato juice was concentrated in the pilot plant scale rotary evaporator, at mild temperature $\left(60^{\circ} \mathrm{C}\right)$ and under vacuum. After adding small amounts of an Italian seasoning mix (dried oregano, marjoram, basil and black pepper, prepared at the OSU pilot plant), $7 \%$ high-fructose maize syrup (both added to improve taste and palatability), and $10 \%$ maize oil to the concentrate on the basis of weight, the mixture was heated to $75^{\circ} \mathrm{C}$ (about $15-20 \mathrm{~min}$ ) in an agitated steam-jacketed vessel and was hot-filled into small cans (type $300 \times 303$ ). After sealing and cooling in an upside-down position, this product was stored to be served as hot-filled tomato sauce rich in all-trans-lycopene (sauce A; $95 \%$ all-trans-lycopene). The second sauce, rich in lycopene cis-isomers (sauce B; 55\% all-trans-lycopene), was obtained by applying the same procedure to the same tomato juice concentrate followed by further processing in a steriotort at $127^{\circ} \mathrm{C}$ for $40 \mathrm{~min}$.

\section{Test meals}

Test meals consisted of tomato sauce $(150 \mathrm{~g})$ served with spaghetti $(200 \mathrm{~g})$ along with a slice $(25 \mathrm{~g})$ of fat-free white wheat bread to absorb the tomato sauce leftover on the plate, and $240 \mathrm{ml}$ bottled water. The energy and macronutrient content of all meals were determined by Food Processor ${ }^{\mathrm{TM}}$ version 8.1 (ESHA Reach, Salem, OR, USA). The test meals provided 2.19 MJ energy, with $29 \%$ of the energy coming from fat, with the remainder being almost entirely carbohydrates. Both tomato sauces were kept in the refrigerator until served to the subjects. They were served at room temperature and added over warm, not hot spaghetti, in order not to cause any possible changes in the carotenoid composition.

\section{Experimental design}

Subjects presented at the clinic on two separate occasions to consume the two tomato sauce meals and were instructed to avoid foods rich in lycopene (especially tomatoes and tomato-containing food products such as pizza, ketchup and lasagne) for 2 weeks as a washout period before each visit. Tomato sauces were served in a randomised cross-over design, each subject acting as his/her own control. Subjects arrived at the OSU General Clinical Research Center after overnight fasting for $12 \mathrm{~h}$. Following a baseline blood draw $(0 \mathrm{~h})$, test meals were served at 08.00 hours and consumed under supervision within $20 \mathrm{~min}$. Consecutive blood samples were collected at $2,3,4,5,6,8$ and $9.5 \mathrm{~h}$ following testmeal consumption. At $4.5 \mathrm{~h}$, subjects consumed a standardised lunch $(120 \mathrm{ml}$ reduced-fat cream of mushroom soup, $15 \mathrm{~g}$ fatfree saltines, light chunk tuna $(56 \mathrm{~g})$ sandwich in two slices of fat-free bread ( $52 \mathrm{~g}$ ), two vanilla sandwich cookies ( $26 \mathrm{~g})$, one bottle of diet soda $(240 \mathrm{ml})$, one bottle of water $(240 \mathrm{ml})$ ) low in carotenoids and fat, providing $1.92 \mathrm{MJ}$ energy from $77 \mathrm{~g}$ carbohydrate, $22 \mathrm{~g}$ protein and $7 \mathrm{~g}$ fat. No other foods and beverages except water (ad libitum) were allowed during the $10 \mathrm{~h}$ clinical visit.

\section{Blood sampling and analysis}

Blood samples $(12 \mathrm{ml})$ drawn from a forearm vein into EDTA tubes were immediately centrifuged for plasma separation at $1250 \mathrm{~g}$ for $10 \mathrm{~min}$ at $4^{\circ} \mathrm{C}$ (Bamon/IEC Division, Needham, MA, USA). Measurements of plasma cholesterol and TAG levels were based on a spectrophotometric enzymatic method (Beckman-Coulter, 2006), using a Synchron LX 20 system (Beckman Coulter Inc., Fullerton, CA, USA). TRL fractions were isolated from plasma by ultracentrifugation at $155000 \mathrm{~g}$ for $30 \mathrm{~min}$ at $20^{\circ} \mathrm{C}$ (Beckman L8-M ultracentrifuge, SW 50.1 swinging bucket rotor) following a method described by van Vliet et al. (1995). 


\section{Carotenoid extractions and quantification}

Carotenoids were extracted from tomato sauces (Ferruzzi et al. 1998) and from the plasma-TRL (Ferruzzi et al. 2001) fraction with acetone-hexane as described previously. All procedures were conducted under red light. Standards of lycopene and $\beta$-carotene were purchased from Sigma Chemicals (St Louis, MO, USA). Stock solutions of carotenoids were prepared in hexane and their concentrations were determined spectrophotometrically, using their specific absorption coefficients (Weast, 1973). All-trans standards were used for the quantification of both trans- and cis-isomers. Analysis of all-translycopene and all-trans- $\beta$-carotene standards indicated no degradation during simulated extraction and on-column during HPLC analysis. Identification of cis-isomers was based on the comparison with previously reported UV-visible spectrophotometry and electrochemical methods (Ferruzzi et al. 1998, 2001; Hadley et al. 2003). Carotenoids were analysed using a Hewlett Packard 1050 HPLC system (Foster City, CA, USA) connected to an electrochemical detector (5600 Coularray ${ }^{\mathrm{TM}}$; ESA, Chelmsford, MA, USA) with cell potentials set from 200 to $620 \mathrm{mV}$ in $60 \mathrm{mV}$ increments. $\mathrm{A} \mathrm{C}_{30}$ column $\left(\mathrm{YMC}^{\mathrm{TM}}, 150 \times 4.6 \mathrm{~mm}, 5 \mu \mathrm{m}\right.$; Waters, Milford, MA, USA) was used for the analysis of carotenoids in conjunction with a gradient method (Ferruzzi et al. 2001).

\section{Statistical analyses}

Postprandial absorption for each carotenoid in the plasmaTRL fraction, expressed as baseline-corrected area under the concentration $v$. time curve (AUC) over $9.5 \mathrm{~h}$ after test-meal consumption, was calculated by trapezoidal approximation using Igor Pro 4.06 software (Wave Metrics, Lake Oswego, OR, USA). Statistical analyses were performed using SAS JMP version 5.0 (SAS Institute, Cary, NC, USA). ANOVA was carried out with multiple covariates (sex, age, BMI, plasma TAG, plasma cholesterol and baseline values) to compare AUC responses between the two tomato sauces. Adjustment of AUC data was made by dividing through the total amount of lycopene consumed. Log-transformation (decadic) of the AUC data was used to improve the statistical modelling and residuals were examined for model compliance. Normality of residuals was checked using the Shapiro-Wilk test.

Baseline-corrected AUC $(\mathrm{nmol} \times \mathrm{h} / \mathrm{l})$ values, peak concentrations $\left(\mathrm{C}_{\max } ; \mathrm{nmol} / \mathrm{l}\right.$, baseline corrected $)$, fractional absorption and carotenoid content $(\mathrm{mg} / 150 \mathrm{~g}$ serving size) of the test meals were expressed as mean values with their standard errors. $P$ values $<0.05$ were considered significant (two-sided). Pearson correlation was calculated and linear regression analyses were performed to study the relationship between $\mathrm{AUC}_{4-6}$ and $\mathrm{AUC}_{0-9.5}$ values. Fractional lycopene absorption from the test meals was estimated according to O’Neill \& Thurnham (1998):

$$
\begin{aligned}
\text { Fractional absorption }= & (\ln 2) / t_{\frac{1}{2}} \times(\text { calculated oral AUC } \\
& \times \text { mass } \times \text { plasma volume }) / \text { oral dose }
\end{aligned}
$$

assuming $t_{\frac{1}{2}}$ of chylomicrons to be $0.192 \mathrm{~h}$, plasma volume (ml) being $927+31.47 \times$ body weight in $\mathrm{kg}$, mass being the molecular weight of lycopene in $\mathrm{g} / \mathrm{mol}$, and oral dose being the amount lycopene consumed in $\mathrm{g}$.
Table 1. Subject characteristics at the onset of the study (Mean values with their standard errors)

\begin{tabular}{lcccccc}
\hline & \multicolumn{2}{c}{ Women $(n 6)$} & & \multicolumn{2}{c}{ Men $(n 6)$} \\
\cline { 2 - 3 } & Mean & SEM & & Mean & SEM \\
\hline Age (years) & 31.3 & 3.7 & & 28.5 & 2.7 \\
BMI (kg/m $\left.{ }^{2}\right)$ & 27.5 & 3.4 & & 26.6 & 1.4 \\
Plasma TAG (mmol//*) & 0.730 & 0.129 & & 1.208 & 0.310 \\
Plasma cholesterol $(\mathrm{mmol} / \mathrm{l} \dagger)$ & 4.07 & 0.06 & & 4.27 & 0.37 \\
\hline
\end{tabular}

* Conversion factor to $\mathrm{mg} / \mathrm{l}$ is $\times 885.7$.

†Conversion factor to $\mathrm{mg} / \mathrm{l}$ is $\times 386 \cdot 7$.

\section{Results}

All recruited subjects (six males, six females; Table 1) completed the study and consumed both test meals. Age, BMI, plasma cholesterol and TAG levels were not significantly different between men and women. Fasting plasma TAG and cholesterol levels were all within the normal reported range $(<2.3 \mathrm{mmol} / \mathrm{l}$ for TAG, and $<5.2 \mathrm{mmol} / \mathrm{l}$ for cholesterol (National Cholesterol Education Program (NCEP) Expert Panel on Detection, Evaluation, \& Treatment of High Blood Cholesterol in Adults (Adult Treatment Panel III), 2002). Effects of sex, age, BMI and plasma cholesterol values were found not to affect carotenoid absorption significantly, while plasma TAG values had a significant effect on carotenoid absorption when these variables were used in the model as covariate, i.e. higher TAG concentrations were significantly associated with higher carotenoid absorption.

Total lycopene (sum of all-trans- and cis-isomers identified as 5-cis-, 9-cis-, 13-cis-, and other unidentified cis-isomers) and $\beta$-carotene (sum of all-trans- and the 9-cis-isomer) content of both sauces per $150 \mathrm{~g}$ serving size are given in Table 2 . The additional heat treatment (steriotort) of sauce A elevated the percentage of lycopene cis-isomers approximately 9-fold in sauce B, resulting in about $45 \%$ cis-isomers of total lycopene. Higher temperatures were also tested; however, setting temperature and time above the chosen parameters of $127^{\circ} \mathrm{C}$ and $40 \mathrm{~min}$ resulted in an unacceptable brown-coloured product in preliminary trials, which was of a burnt taste. Because the two tomato sauces were processed in two different batches, DM content was slightly different, Brix values* for sauce A and B being 20.8 (SEM 0.09) and 19.6 (SEM 0.07) ( $n$ 10), respectively. As the total lycopene and $\beta$-carotene contents of the two sauces were not exactly the same in the final product, plasma-TRL AUC responses between the two sauces were compared on both a lycopene-dose-adjusted and non-adjusted basis (Table 3).

In addition to the all-trans form, several cis-isomers of lycopene as identified by Hadley et al. (2003) were detected in the plasma-TRL fraction obtained after test-meal consumption (Table 3). Thus, results are expressed as all-trans-lycopene, total lycopene cis-isomers including 5-cis-, 9-cis- and 13-cis-isomers, and total lycopene. In addition, low amounts of all-trans- $\beta$-carotene along with its 9-cis-isomer were detected. The oral $\beta$-carotene dose consumed with the tomato sauce was relatively low, and subjects were only on a lycopene-free diet and not on a $\beta$-carotene-free diet during the washout period. Thus, enrichment of $\beta$-carotene after

\footnotetext{
* Brix values are the measurement of the specific density of a solution A solution has $1^{\circ}$ Brix if the density is equal to $100 \mathrm{~g}$ water containing $1 \mathrm{~g}$ sucrose.
} 
Table 2. Carotenoid profile of the test meals $†$ (Mean values with their standard errors)

\begin{tabular}{|c|c|c|c|c|}
\hline \multirow[b]{2}{*}{ Compound } & \multicolumn{2}{|c|}{$\begin{array}{l}\text { Hot fill } \\
\text { (sauce } A)\end{array}$} & \multicolumn{2}{|c|}{$\begin{array}{l}\text { Steriotort } \\
\text { (sauce B) }\end{array}$} \\
\hline & Mean & SEM & Mean & SEM \\
\hline Total lycopene (mg/150 g) & $48 \cdot 69^{\star \star *}$ & 1.33 & 39.65 & 1.00 \\
\hline All-trans-lycopene $(\mathrm{mg} / 150 \mathrm{~g})$ & $46 \cdot 16^{\star \star \star}$ & $1 \cdot 28$ & $21 \cdot 68$ & $0 . \varepsilon$ \\
\hline $\begin{array}{l}\text { Total cis-lycopene isomers } \\
(\mathrm{mg} / 150 \mathrm{~g})\end{array}$ & $2 \cdot 53^{\star \star \star}$ & 0.12 & 17.96 & 0.26 \\
\hline 13-cis-lycopene (mg/150 g) & $1.71^{\star \star \star}$ & 0.10 & $6 \cdot 47$ & 0.20 \\
\hline 9-cis-lycopene (mg/150 g) & $0.44^{\star * *}$ & 0.04 & $6 \cdot 27$ & 0.14 \\
\hline 5-cis-lycopene (mg/150 g) & ND & - & ND & 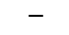 \\
\hline Total $\beta$-carotene (mg/150 g) & $3.95^{\star \star}$ & 0.17 & $2 \cdot 48$ & 0.16 \\
\hline 9-cis- $\beta$-carotene $(\mathrm{mg} / 150 \mathrm{~g})$ & 0.47 & 0.18 & 0.46 & 0.13 \\
\hline
\end{tabular}

ND, not detectable.

Mean value was significantly different from that for sauce $\mathrm{B}$ : ${ }^{*} P<0.05$, ${ }^{\star *} P<0.01$, ${ }^{\star * \star} P<0.001$ (Fisher $F$ test).

$\dagger$ Values are based on serving size $(n 6)$

test-meal intake in the plasma-TRL fraction was relatively low, and is therefore not reported.

When comparing the percentage of cis-isomers of total lycopene in the sauce $v$. the plasma-TRL fraction, an average increase from approximately 5 to $42 \%$ was observed for sauce A. For sauce B, this percentage increased from 45 to $52 \%$ (Fig. 1). Similarly, trans:cis-lycopene abundance ratios were 18.2 in sauce A and 1.4 in the plasma-TRL AUC of the group consuming this sauce, while this ratio was 1.2 and 0.9 for sauce B, respectively.

Baseline-corrected, dose-adjusted peak concentrations of 0.45 (SEM 0.11) and 0.73 (SEM 0.14) nmol/1 plasma-TRL for total lycopene cis-isomers and 0.98 (SEM 0.25) and 1.38 (SEM 0.25$) \mathrm{nmol} / \mathrm{l}$ plasma-TRL for total lycopene were reached in the plasma-TRL fraction at the 5th hour after the consumption of sauce A and sauce B, respectively (Fig. 2).

A strong significant correlation $(P<0 \cdot 0001)$ between the shortened approach to determine lycopene TRL AUC based on four blood samples $\left(\mathrm{AUC}_{4-6}\right) v$. $\mathrm{AUC}_{0-9.5}$ was found for total lycopene, lycopene cis-isomers and all-trans-lycopene (log-transformed (decadic) data, dose adjusted and baseline corrected). A linear model was developed to estimate the $\mathrm{AUC}_{0-9.5}$ by using $\mathrm{AUC}_{4-6}$ as:

$$
\begin{aligned}
& \log \left(\text { total lycopene } \mathrm{AUC}_{0-9.5}\right)=0.537+0.834 \\
& \times\left(\text { total lycopene } \mathrm{AUC}_{4-6}\right) \quad\left(r^{2} 0 \cdot 912\right) ; \\
& \log \left(\text { total } c i s-\text { lycopene } \mathrm{AUC}_{0-9.5}\right)=0.477+0.790 \\
& \times\left(\text { cis - lycopene } \mathrm{AUC}_{4-6}\right) \quad\left(r^{2} 0 \cdot 875\right) \text {; } \\
& \log \left(\text { all - trans - lycopene } \mathrm{AUC}_{0-9.5}\right)=0.504+0 \cdot 860 \\
& \times\left(\text { all - trans - lycopene } \mathrm{AUC}_{4-6}\right) \quad\left(r^{2} 0 \cdot 920\right) ; \\
& \log \left(5-\text { cis }- \text { lycopene } \mathrm{AUC}_{0-9.5}\right)=0 \cdot 380+0 \cdot 680 \\
& \times\left(5-\text { cis - lycopene } \mathrm{AUC}_{4-6}\right) \quad\left(r^{2} 0 \cdot 755\right) \text {; } \\
& \log \left(9-\text { cis - lycopene } \mathrm{AUC}_{0-9.5}\right)=0.506+1.035 \\
& \times\left(9-c i s-\text { lycopene } \mathrm{AUC}_{4-6}\right) \quad\left(r^{2} 0 \cdot 999\right) \text {; } \\
& \log \left(13-\text { cis - lycopene } \mathrm{AUC}_{0-9.5}\right)=0.487+1.015 \\
& \times\left(13-c i s-\text { lycopene } \mathrm{AUC}_{4-6}\right) \quad\left(r^{2} 0.995\right) .
\end{aligned}
$$

\begin{tabular}{|c|c|c|c|c|c|c|c|c|c|c|c|c|c|}
\hline & \multirow[b]{2}{*}{ Sauce } & \multicolumn{2}{|c|}{$\begin{array}{l}\text { All-trans- } \\
\text { lycopene }\end{array}$} & \multicolumn{2}{|c|}{$\begin{array}{c}\text { Total } \\
\text { cis-isomers }\end{array}$} & \multicolumn{2}{|c|}{$\begin{array}{c}\text { 9-cis- } \\
\text { Iycopene }\end{array}$} & \multicolumn{2}{|c|}{$\begin{array}{l}\text { 13-cis- } \\
\text { lycopene }\end{array}$} & \multicolumn{2}{|c|}{$\begin{array}{l}5 \text {-cis- } \\
\text { lycopene }\end{array}$} & \multicolumn{2}{|c|}{$\begin{array}{c}\text { Total } \\
\text { lycopene }\end{array}$} \\
\hline & & Mean & SEM & Mean & SEM & Mean & SEM & Mean & SEM & Mean & SEM & Mean & SEM \\
\hline \multirow[t]{2}{*}{$\mathrm{AUC}_{0-9.5}(\mathrm{nmol} \times \mathrm{h} / \mathrm{l})$} & A & 134.4 & $37 \cdot 0$ & $96 \cdot 2$ & $18 \cdot 1$ & 11.5 & 2.6 & $34 \cdot 6$ & $7 \cdot 9$ & $38 \cdot 6$ & $6 \cdot 1$ & $230 \cdot 7$ & 52.5 \\
\hline & B & $138 \cdot 8$ & 29.9 & $150 \cdot 8^{*}$ & $30 \cdot 0$ & $50 \cdot 4^{\star \star \star}$ & $10 \cdot 0$ & $38 \cdot 2$ & $7 \cdot 6$ & 47.5 & 7.5 & $289 \cdot 6^{*}$ & $57 \cdot 6$ \\
\hline \multirow{2}{*}{$\begin{array}{l}\text { Adjusted } \mathrm{AUC}_{0-9.5} \\
\quad(\mathrm{nmol} \times \mathrm{h} / \mathrm{l}) \ddagger\end{array}$} & A & $2 \cdot 76$ & 0.76 & 1.98 & 0.37 & 0.24 & 0.05 & 0.71 & 0.16 & 0.79 & 0.13 & $4 \cdot 74$ & 1.08 \\
\hline & $\mathrm{B}$ & $3 \cdot 50^{*}$ & 0.76 & $3 \cdot 80^{\star * *}$ & 0.76 & $1 \cdot 27^{\star \star \star}$ & 0.25 & $0.96^{*}$ & 0.19 & $1 \cdot 20^{*}$ & 0.19 & $7 \cdot 30^{\star *}$ & 1.45 \\
\hline \multirow[t]{2}{*}{$\mathrm{AUC}_{4-6}(\mathrm{nmol} \times \mathrm{h} / \mathrm{l})$} & $A$ & $45 \cdot 5$ & $13 \cdot 3$ & $34 \cdot 4$ & $8 \cdot 0$ & $4 \cdot 0$ & $1 \cdot 1$ & $12 \cdot 1$ & $3 \cdot 2$ & $13 \cdot 6$ & 2.9 & $79 \cdot 8$ & $20 \cdot 3$ \\
\hline & B & $44 \cdot 2$ & $10 \cdot 6$ & $48 \cdot 6^{*}$ & $10 \cdot 3$ & $16 \cdot 1^{\text {***}}$ & 3.5 & $12 \cdot 2$ & $2 \cdot 7$ & $15 \cdot 0$ & 2.7 & 92.5 & $20 \cdot 3$ \\
\hline \multirow{2}{*}{ 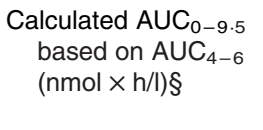 } & A & $2 \cdot 89$ & 0.71 & $2 \cdot 16$ & 0.41 & 0.24 & 0.06 & 0.75 & 0.17 & 0.96 & 0.14 & 4.99 & 1.05 \\
\hline & $\mathrm{B}$ & $3 \cdot 40^{*}$ & 0.69 & $3 \cdot 39^{\star \star}$ & 0.57 & $1 \cdot 27^{\star \star \star}$ & 0.26 & 0.93 & $0 \cdot 19$ & $1 \cdot 19^{\star \star}$ & $0 \cdot 15$ & $6 \cdot 73^{\star *}$ & $1 \cdot 24$ \\
\hline \multirow[t]{2}{*}{$\mathrm{C}_{\max }(\mathrm{nmol} / \mathrm{l})$} & A & $26 \cdot 0$ & 7.5 & 21.9 & $5 \cdot 4$ & 2.9 & 0.8 & $7 \cdot 4$ & $1 \cdot 8$ & $8 \cdot 8$ & $2 \cdot 0$ & $47 \cdot 8$ & $12 \cdot 1$ \\
\hline & $B$ & $25 \cdot 7$ & $5 \cdot 0$ & $29 \cdot 1^{*}$ & 5.4 & $9 \cdot 8^{* * *}$ & $2 \cdot 2$ & 6.9 & 1.5 & 9.7 & 1.6 & $54 \cdot 8$ & $10 \cdot 0$ \\
\hline \multirow{2}{*}{$\begin{array}{l}\text { Fractional } \\
\text { absorption (\%) }\end{array}$} & A & 1.90 & 0.59 & $1 \cdot 29$ & $0 \cdot 24$ & 0.16 & 0.04 & 0.48 & 0.12 & 0.52 & 0.07 & $3 \cdot 19$ & 0.80 \\
\hline & B & $2 \cdot 40^{*}$ & 0.59 & $2 \cdot 57^{\star \star *}$ & 0.53 & $0.86^{\star * *}$ & 0.19 & $0.66^{*}$ & 0.14 & $0.80^{*}$ & 0.13 & $4.97^{* *}$ & 1.08 \\
\hline
\end{tabular}

Table 3. Distribution of lycopene isomers in plasma triacylglycerol-rich lipoprotein fractions following the consumption of tomato sauces in human subjects $†$ (Mean values with their standard errors)

AUC, area under the curve; $\mathrm{C}_{\max }$, peak concentration.

Mean value was significantly different from that for sauce A: ${ }^{\star} P<0.05$, ${ }^{\star \star} P<0.005,{ }^{\star \star \star}{ }^{*} P<0.0005$ (Fisher $F$ test; tests based on log-transformed data).

†All values are based on $n 12$. All values are baseline corrected. Test meals consisted of $150 \mathrm{~g}$ tomato sauce, served together with $200 \mathrm{~g}$ spaghetti and $25 \mathrm{~g}$ white wheat bread. $\ddagger$ Adjustment was done by dividing through the amount of total lycopene served in the test meal.

$\S$ Values are dose adjusted for the total amount of lycopene consumed. The method is based on only four blood samples drawn at $0,4,5$ and $6 \mathrm{~h}$ following test-meal consumption. No significant differences were detected compared with the measured values (adjusted $\mathrm{AUC}_{0-9.5)}$. 

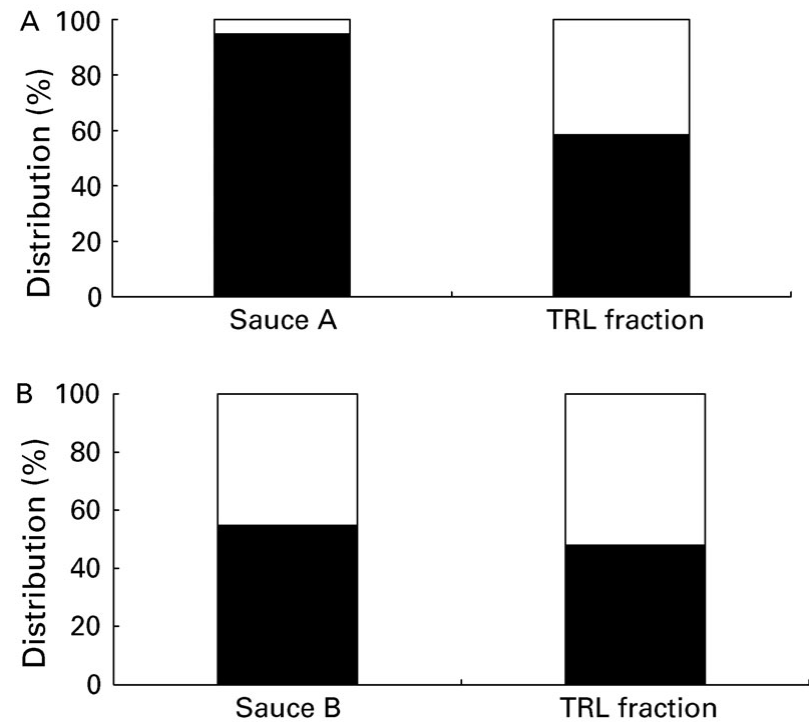

Fig. 1. Percentage distribution of lycopene isomers in the tomato sauces and the mean response in the plasma TAG-rich lipoprotein (TRL) fraction measured as baseline-corrected area under the curve after consumption of sauce A, rich in all-trans-lycopene $(\square)(A)$ and sauce $B$, rich in cis-lycopene ( $\square$ ) (B), respectively.

To validate the novel approach to determine lycopene TRL AUC and therefore to determine absorption, the $\mathrm{AUC}_{4-6}$ values were used to calculate the $\mathrm{AUC}_{0-9.5}$ values with the above equations and then compared with the observed values for total lycopene, all-trans-lycopene, total cis-lycopene and its isomers. No significant differences were found between the calculated and the measured results (Table 3).

\section{Discussion}

The results of the present study demonstrate a more than $55 \%$ increase in fractional total lycopene absorption following the consumption of a cis-lycopene-rich tomato sauce $v$. a very similar all-trans-rich tomato sauce. In addition, the study shows an enhanced cis- compared with all-trans-lycopene

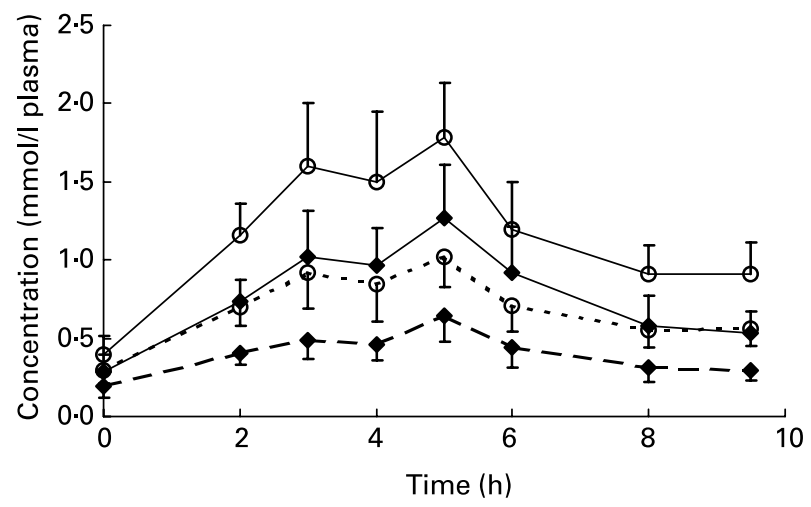

Fig. 2. Dose-adjusted plasma TAG-rich lipoprotein concentrations of total lycopene and lycopene cis-isomers following the consumption of sauce $A$ (rich in all-trans-lycopene) and sauce B (rich in cis-lycopene) over $9.5 \mathrm{~h}$. Values are means ( $n$ 12), with standard errors represented by vertical bars. $(-\diamond)$, Total lycopene in sauce A; $(-\bigcirc-)$, total lycopene in sauce $B$; $(-\bullet-$, dotted line), cis-lycopene in sauce $\mathrm{A} ;\left(-\mathrm{O}_{-}\right.$, dotted line), cis-lycopene in sauce $B$.
plasma-TRL response when taking into account the amount of isomer consumed. These findings are in line with the hypothesis of preferential absorption of lycopene cis-isomers. To our knowledge, this is the first human study demonstrating enhanced $c i s$-lycopene-isomer response compared with its alltrans-isomer from tomato products with a common food matrix, similar to those commercially available.

In the present study, cis-lycopene formation was controlled in the all-trans-lycopene-rich tomato sauce by applying a mild processing temperature of $75^{\circ} \mathrm{C}$, resulting in $5 \%$ cis-isomer formation. Cis-lycopene formation was induced to $45 \%$ of total lycopene in a sauce by adjusting the temperature to $127^{\circ} \mathrm{C}$ (40 min). The published literature regarding the effects of tomato processing on the formation of lycopene cis-isomers remains somewhat controversial. Nguyen \& Schwartz (1998), Nguyen et al. (2001) and Re et al. (2002) have shown that modest thermal treatment did not cause a considerable shift in the distribution of trans:cis-lycopene isomers. However, the addition of fat, together with applying higher temperatures, such as may occur during the cooking of tomato products, has been suggested to cause an increase in lycopene cis-isomer formation during tomato processing. Agarwal et al. (2001) observed an increase from 6 to $29 \%$ cis-isomers when heating tomato juice $(1 \mathrm{~h})$ with $10 \%$ added maize oil. Similarly, van het Hof et al. (1998) found elevated levels of cis-isomers (about $55 \%$ ) when tomato paste was heated to $100^{\circ} \mathrm{C}$ for $30 \mathrm{~min}$ in the presence of $10 \%$ maize oil, whereas it was lower with $5 \%$ oil addition (about $35 \%$ ) and low (about $5 \%$ ) in the absence of oil. Together, these studies suggest that most processed food products contain primarily alltrans-lycopene, but that additional processing or cooking methods could increase cis-lycopene content. In the present study, the addition of $10 \%$ maize oil to both sauces before processing resulted in the formation of cis-lycopene isomers with concentrations comparable with the former studies. It can be speculated that a certain amount of fat needs to be present in the product to solubilise and release lycopene from the matrix to enhance isomerisation by thermal treatment.

Although estimated total lycopene and isomer content of the two tomato sauces differed, we understand that the HPLC method used to quantify isomers is limited by the fact that pure authentic standards of isomers are not readily available for calibration. Measurements for all detected lycopene isomers are based on response factors for the all-trans compound. When using UV-visible spectrophotometry methods of detection, this would result in an underestimation of lycopene isomer content because of the shift in absorbance spectra when isomerisation occurs. Electrochemical methods of detection were found to be similar in detector response to all-translycopene but not for all lycopene isomeric forms (Ferruzzi et al. 2001). As such, further refinements in methodology are necessary to quantify lycopene cis-isomers including other cis-carotenoid geometrical forms.

Previous studies (Stahl \& Sies, 1992; Gartner et al. 1997) have suggested that heat treatment alone might improve lycopene bioavailability without significantly altering the isomer composition within foods. In the present study, it is therefore possible that the higher lycopene absorption from the cisisomer-rich product was due to the higher temperature treatment. The observation that not only the cis-lycopene plasma-TRL response, but also the all-trans-lycopene 
response increased following consumption of the cis-lycopene-rich product as compared with the all-trans-rich product, would support this hypothesis. However, in another study by our group (Unlu et al. 2007), we found a significantly higher plasma-TRL response from tomato sauce obtained from tangerine tomatoes rich in cis-lycopene (about $97 \%$ cis-isomers) produced under similar mild processing conditions as compared with the all-trans-rich tomato sauce in the present study. Thus, both preferred absorption of lycopene cis-isomers per se, and improved absorption of total lycopene due to heat treatment could have contributed to the present results, as the effect of cis-lycopene isomerisation could not be separated from the heat processing. In addition to heat treatment, the lower dose of lycopene served within the cisisomer-rich sauce could have added to an increased fractional lycopene absorption, as lycopene absorption has been reported to follow a curvilinear absorption pattern, as tested with doses ranging between 10 and $120 \mathrm{mg}$ (Gustin et al. 2004). However, in the present study, even the non-dose-adjusted AUC suggested higher lycopene bioavailability from the cisisomer-rich lycopene product.

The main mechanism by which cis-lycopene accumulates in blood or tissue remains controversial. The higher plasma-TRL responses of cis-lycopene and its isomers compared with alltrans-lycopene (when taking into account the amount isomer consumed) from both, but especially from the all-trans-lycopene-rich product, could be explained either due to higher absorption of cis-lycopene, increased in vivo isomerisation from all-trans-lycopene, or both. The observation, however, that following consumption of the cis-rich product, only a slightly decreased ratio of trans:cis-lycopene was found in the TRL fraction indicated that an enhanced uptake of cis-lycopene alone cannot explain the observed results. This less pronounced difference in isomer composition between the plasma-TRL fraction and the tomato sauce consumed indicated that isomerisation continued toward an equilibrium between all-trans- and cislycopene isomers in the plasma-TRL fraction. An earlier in vitro study investigating trans:cis-isomer distribution in organic solutions suggested a ratio of $50 \%$ all-trans- to $50 \%$ cis-lycopene to be the most stable (Nguyen \& Schwartz, 1998), values which are close to the ones observed in the plasma-TRL fractions of the present study. The trans:cis-isomer ratio of the plasma-TRL fraction was 0.92 and 1.39 following the cis-lycopene and all-trans-lycopene-rich sauce consumption, respectively, suggesting that the higher the trans:cis-isomer ratio in the product consumed, the higher the trans:cis ratio in the TRL AUC response. Boileau et al. (1999) found significantly higher amounts of cis-lycopene isomers in mesenteric lymph (77\%) compared with dose, stomach and intestinal contents $(6-18 \%)$ in ferrets. It has thus been suggested that there is a continuous isomerisation of all-trans-lycopene to cis-lycopene isomers in the body, with higher proportions of cis-lycopene following the order tissue $>$ serum $>$ chylomicrons (Clinton et al. 1996). This is further supported by a previous human study by the observation that upon cessation of dietary (predominantly all-trans) lycopene intake, the percentage of cis-isomers of total lycopene increases in plasma (Frohlich et al. 2006). Interestingly, the present study additionally indicates in vivo isomerisation of either all-trans- or cis-isomers of lycopene to 5-cis-lycopene, as this was not detected in the tomato sauce, while it was found in high concentrations in the plasma-TRL fractions following sauce consumption. As formation of 5-cis from other cis-isomers would require several isomerisation steps, and all-trans-lycopene was present in much higher concentration in the product and plasma-TRL, it appears more likely that all-trans-lycopene was isomerised to 5-cis-lycopene in vivo. 9-cis- and 13-cis-lycopene were present in both sauce and plasma-TRL, and their presence can thus be explained by absorption.

The carotenoid response measured in the TRL-fraction of plasma was suggested to be a valuable measure of carotenoid bioavailability from single meals, as this fraction represents newly absorbed carotenoids (O’Neill \& Thurnham, 1998). However, a large number of blood samples over a $10-12 \mathrm{~h}$ course are often employed. We found a significant correlation between TRL $\mathrm{AUC}_{4-6}$ and $\mathrm{AUC}_{0-9.5}$ following the consumption of test meals for total lycopene, lycopene cis-isomers and all-trans-lycopene, and a linear model was developed to estimate the $\mathrm{AUC}_{0-9.5}$ values based on the $\mathrm{AUC}_{4-6}$. No significant differences in the $\mathrm{AUC}$ were found when comparing the estimated $\mathrm{AUC}_{0-9.5}$ values (based on the $\mathrm{AUC}_{4-6}$ ) with the measured $\mathrm{AUC}_{0-9.5}$. Thus, in future studies comparing lycopene bioavailability from different test meals, it seems feasible to collect only four blood samples at $0,4,5$ and $6 \mathrm{~h}$ following test-meal consumption. The limited data obtained within the present study suggest a similar kinetic behaviour of the cisisomers and all-trans-lycopene within the plasma-TRL fraction during the observed $9.5 \mathrm{~h}$ time period, as the TRL appearance pattern, $\mathrm{C}_{\max }$, and the similar regression curves for estimating the $\mathrm{AUC}_{0-9.5}$ based on the $\mathrm{AUC}_{4-6}$ values indicate. As a smaller number of samples are beneficial both for the researcher and subject, future studies to extend this method to additional carotenoids are merited.

In conclusion, we observed a significant increase in lycopene absorption when tomato sauce was enriched in cis-isomers by heat treatment, being in agreement with the hypothesis that cis-lycopene isomers are preferentially absorbed in man. Additional heat treatment of the tomato matrix, enhancing availability of lycopene to digestive and absorptive processes, could also have contributed to this result. The present results further suggest that preferred absorption of cis-lycopene isomers alone cannot explain the dramatically increased proportion of lycopene cis-isomers in biological samples, an observation that probably reflects an additional in vivo isomerisation from all-trans- to cis-isomers. However, based upon these findings, tomato-based food products could be manipulated by temperature processing to favour the formation of specific isomer patterns to improve lycopene bioavailability and possibly health benefits.

\section{Acknowledgements}

Salaries and research support were provided by state and federal funds appropriated to: The OSU (Ohio Agricultural Research and Development Center (OARDC) Competitive Grants Program); The General Clinical Research Center at The OSU (grant M01-RR00034 from the National Center of Research Resources of the National Institutes of Health); National Cancer Institute grant RO1 CA 112632; the United States Department of Agriculture Initiative for Future Agriculture \& Food Systems (IFAFS) grant no. 2001-52102-11333. 


\section{References}

Agarwal A, Shen H, Agarwal S \& Rao AV (2001) Lycopene content of tomato products: Its stability, bioavailability and in vivo antioxidant properties. J Med Food 4, 9-15.

Beckman-Coulter (2006) SYNCHRON LX* system(s) chemistry information sheets for cholesterol and triglycerides. http://www. beckmancoulter.com/products/testmenu/synchron.asp.

Boileau AC, Merchen NR, Wasson K, Atkinson CA \& Erdman JW (1999) Cis-lycopene is more bioavailable than trans-lycopene in vitro and in vivo in lymph-cannulated ferrets. J Nutr 129, 1176-1181.

Clinton SK, Emenhiser C, Schwartz SJ, Bostwick DG, Williams AW, Moore BJ \& Erdman JW Jr (1996) Cis-trans lycopene isomers, carotenoids, and retinol in the human prostate. Cancer Epidemiol Biomarkers Prev 5, 823-833.

Erdman JW (2005) How do nutritional and hormonal status modify the bioavailability, uptake, and distribution of different isomers of lycopene? J Nutr 135, 2046S-2047S.

Ferruzzi MG, Nguyen ML, Sander LC, Rock CL \& Schwartz SJ (2001) Analysis of lycopene geometrical isomers in biological microsamples by liquid chromatography with coulometric array detection. J Chromatogr 760B, 289-299.

Ferruzzi MG, Sander LC, Rock CL \& Schwartz SJ (1998) Carotenoid determination in biological microsamples using liquid chromatography with a coulometric electrochemical array detector. Anal Biochem 256, 74-81.

Frohlich K, Kaufmann K, Bitsch R \& Bohm V (2006) Effects of ingestion of tomatoes, tomato juice and tomato puree on contents of lycopene isomers, tocopherols and ascorbic acid in human plasma as well as on lycopene isomer pattern. Br J Nutr 95, 734-741.

Gartner C, Stahl W \& Sies H (1997) Lycopene is more bioavailable from tomato paste than from fresh tomatoes. Am J Clin Nutr 66, $116-122$

Giovannucci E (1999) Tomatoes, tomato-based products, lycopene, and cancer: review of the epidemiologic literature. J Natl Cancer Inst 91, 317-331.

Gustin DM, Rodvold KA, Sosman JA, Diwadkar-Navsariwala V, Stacewicz-Sapuntzakis M, Viana M, Crowell JA, Murray J, Tiller P \& Bowen PE (2004) Single-dose pharmacokinetic study of lycopene delivered in a well-defined food-based lycopene delivery system (tomato paste-oil mixture) in healthy adult male subjects. Cancer Epidemiol Biomarkers Prev 13, 850-860.

Hadley CW, Clinton SK \& Schwartz SJ (2003) The consumption of processed tomato products enhances plasma lycopene concentrations in association with a reduced lipoprotein sensitivity to oxidative damage. J Nutr 133, 727-732.

Khachik F, Carvalho L, Bernstein PS, Muir GJ, Zhao DY \& Katz NB (2002) Chemistry, distribution, and metabolism of tomato carotenoids and their impact on human health. Exp Biol Med 227, $845-851$

Korytko PJ, Rodvold KA, Crowell JA, Stacewicz-Sapuntzakis M, Diwadkar-Navsariwala V, Bowen PE, Schalch W \& Levine BS (2003) Pharmacokinetics and tissue distribution of orally administered lycopene in male dogs. J Nutr 133, 2788-2792.
McEligot AJ, Rock CL, Shanks TG, Flatt SW, Newman V, Faerber S \& Pierce JP (1999) Comparison of serum carotenoid responses between women consuming vegetable juice and women consuming raw or cooked vegetables. Cancer Epidemiol Biomarkers Prev 8, $227-231$.

National Cholesterol Education Program (NCEP) Expert Panel on Detection, Evaluation, and Treatment of High Blood Cholesterol in Adults (Adult Treatment Panel III) (2002) Third Report of the National Cholesterol Education Program (NCEP) Expert Panel on Detection, Evaluation, and Treatment of High Blood Cholesterol in Adults (Adult Treatment Panel III) final report. Circulation 106, 3143-3421.

Nguyen ML, Francis D \& Schwartz SJ (2001) Thermal isomerisation susceptibility of carotenoids in different tomato varieties. $J \mathrm{Sci}$ Food Agric 81, 910-917.

Nguyen ML \& Schwartz SJ (1998) Lycopene stability during food processing. Proc Soc Exp Biol Med 218, 101-105.

Nguyen ML \& Schwartz SJ (2000) Natural Food Colorants: Science and Technology, 1st ed. New York: Marcel Dekker.

O'Neill ME \& Thurnham DI (1998) Intestinal absorption of $\beta$-carotene, lycopene and lutein in men and women following a standard meal: response curves in the triacylglycerol-rich lipoprotein fraction. Br J Nutr 79, 149-159.

Precheur RJ (2000) Ohio Vegetable Production Guide. The Ohio State University Cooperative Extension Bulletin no. 672. Columbus, OH: Ohio State University.

Rao AV (2004) Processed tomato products as a source of dietary lycopene: bioavailability and antioxidant properties. Can J Diet Pract Res 65, 161-165.

Re R, Bramley PM \& Rice-Evans C (2002) Effects of food processing on flavonoids and lycopene status in a Mediterranean tomato variety. Free Radic Res 36, 803-810.

Schierle J, Bretzel W, Bühler I, Faccin N, Hess D, Steiner K \& Schüep W (1997) Content and isomeric ratio of lycopene in food and human blood plasma. Food Chem 59, 459-465.

Shi J \& Le Maguer M (2000) Lycopene in tomatoes: chemical and physical properties affected by food processing. Crit Rev Biotechnol 20, 293-334.

Stahl W \& Sies H (1992) Uptake of lycopene and its geometrical isomers is greater from heat-processed than from unprocessed tomato juice in humans. J Nutr 122, 2161-2166.

Unlu NZ, Bohn T, Francis DM, Clinton SK \& Schwartz SJ (2007) Carotenoid absorption in humans consuming tomato pasta sauces obtained from tangerine or high- $\beta$-carotene varieties of tomatoes. J Agric Food Chem. Published online. doi: 10.1021/jf062337b.

van het Hof KH, Gartner C, West CE \& Tijburg LBM (1998) Potential of vegetable processing to increase the delivery of carotenoids to man. Int J Vitam Nutr Res 68, 366-370.

van Vliet T, Schreurs W \& van den Berg H (1995) Intestinal $\beta$-carotene absorption and cleavage in men: response of $\beta$-carotene and retinyl esters in the triglyceride-rich lipoprotein fraction after a single oral dose of $\beta$-carotene. Am J Clin Nutr 62, 110-116.

Weast R (1973) Handbook of Chemistry and Physics. Cleveland, OH: CRC Press. 